\title{
Safety and efficacy of acarbose in the treatment of diabetes in Chinese patients
}

This article was published in the following Dove Press journal:

Therapeutics and Clinical Risk Management

30 June 2014

Number of times this article has been viewed

\section{$\mathrm{Ke} \mathrm{He}$ * \\ Jun-Cheng Shi* \\ Xiao-Ming Mao}

Department of Endocrinology, Nanjing First Hospital Affiliated to Nanjing Medical University, Nanjing, People's Republic of China

*These authors contributed equally to this work

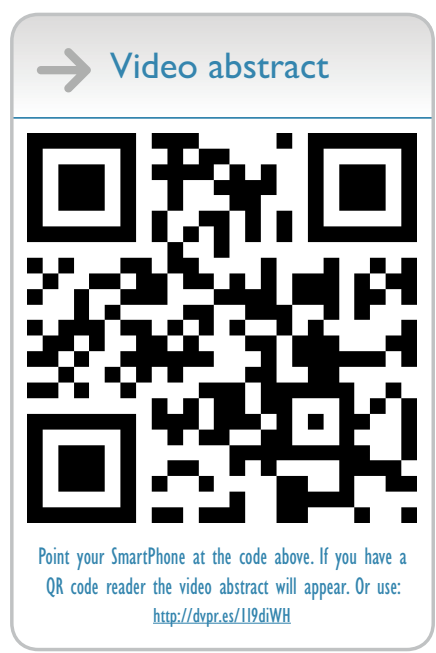

Correspondence: XM Mao

Department of Endocrinology, Nanjing

First Hospital Affiliated to Nanjing

Medical University, 68 ChangLe St,

Nanjing, 210006, People's Republic of

China

Email maoxming@।63.com
Abstract: Acarbose is an $\alpha$-glucosidase inhibitor that is commonly used to control postprandial blood glucose. It functions as a competitive and reversible inhibitor of small intestinal brush border glucosidase, blocks the degradation of starch and sucrose, and delays the absorption of glucose and fructose in the alimentary tract. The starch content of a diet might alter the hypoglycemic effects of acarbose because of its mechanism of action. Chinese individuals consume a typical Eastern diet, which is characterized by a high intake of whole grains, legumes, vegetables, fruits, and fish. These dietary habits allow acarbose to be used extensively in the People's Republic of China. Several Chinese-based studies have demonstrated that the use of acarbose as a monotherapy had similar effects on other anti-diabetes agents in decreasing glycosylated hemoglobin $\left(\mathrm{HbA}_{1 \mathrm{c}}\right)$ and blood glucose levels, and acarbose in combination with other anti-diabetic drugs could further reduce blood glucose and decrease the mean amplitude of glycemic excursions. Importantly, acarbose is safe and well tolerated, with a low incidence of adverse effects. This article provides a comprehensive review of the safety and efficacy of acarbose for the treatment of diabetes in Chinese patients.

Keywords: acarbose, $\alpha$-glucosidase inhibitor, efficacy, safety

\section{Introduction}

Type 2 diabetes mellitus (T2DM) is a major global health problem, and an increasing cause of morbidity and mortality. However, the etiology and pathogenesis of T2DM are not fully understood. Controlling blood glucose in diabetic patients continues to be a major therapeutic strategy. Accumulating evidence has revealed that the effective control of blood glucose could reduce various diabetic complications. ${ }^{1-4}$ Furthermore, the UK Prospective Diabetes Study reported that the benefits of tight blood glucose control extended well beyond the end of the study, and even persisted for 10 years. ${ }^{5}$ Postprandial glucose is a key predictor of premature death ${ }^{6-8}$ that contributes to hyperglycemia and elevated glycosylated hemoglobin $\left(\mathrm{HbA}_{1 \mathrm{c}}\right)$ levels. ${ }^{9-12}$ Therefore, controlling post-prandial glucose is very important for reducing $\mathrm{HbA}_{1 \mathrm{c}}$ levels and preventing diabetic complications in patients with T2DM.

Alpha-glucosidase inhibitors (AGIs), such as acarbose, are commonly used oral hypoglycemic agents in the People's Republic of China. AGIs primarily target $\alpha$-glucosidase in the small intestine, where $\alpha$-glucosidase catabolizes non-absorbable complex carbohydrates into absorbable monosaccharides. Acarbose is a competitive and reversible inhibitor of small intestinal brush border glucosidase, which blocks the degradation of starch and sucrose, and delays the absorption of glucose and fructose in the upper small bowel (Figure 1). ${ }^{13}$ This reduces blood glucose concentrations, particularly postprandial levels. ${ }^{14-16}$ 


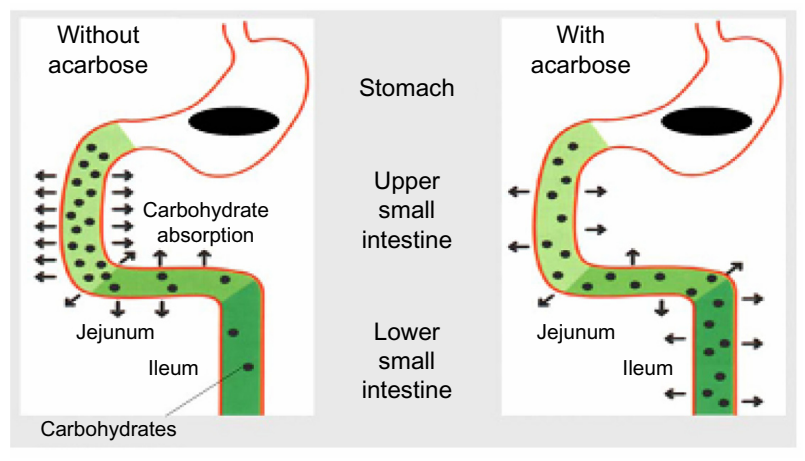

Figure I Acarbose acts non-systemically to delay carbohydrate absorption.

Dietary starch content might alter the hypoglycemic effect of acarbose because of its mechanism of action. A metaanalysis was performed to compare the differences in the hypoglycemic effect of acarbose in Eastern and Western individuals according to the starch content of their diets. The results suggested that acarbose exerts more potent hypoglycemic effects in T2DM patients who consume an Eastern diet than in those consuming a Western diet; its effects were similar to sulfonylureas, metformin, and glinides. ${ }^{17}$

Diets evolve over time, and income, food prices, individual preferences and beliefs, and cultural traditions, as well as geographical, environmental, social, and economic factors, all interact in a complex way to shape dietary habits. Food consumption in Eastern individuals is characterized by a higher intake of whole grains, legumes, vegetables, fruits, and fish, whereas a Western diet is characterized by a higher intake of processed meat, red meat, butter, high-fat dairy products, eggs, and refined grains. ${ }^{18}$ Although Asian diets in recent years have shifted away from cereals and toward a more typical Western pattern of animal and dairy products, fats, and oils concurrent with rapid economic growth, urbanization, and globalization in this region, at least $50 \%-60 \%$ of the total calories in Asians are still obtained from cereals. ${ }^{19}$

Acarbose was first marketed in the People's Republic of China in 1995 as an oral agent used mainly to regulate postprandial glucose in patients with T2DM. A lot of clinical evidence has suggested that acarbose is an effective drug for controlling postprandial glucose in Chinese patients with T2DM. ${ }^{20-25}$ Recently, a study based in Chinese patients with T2DM demonstrated that acarbose had a similar efficacy to metformin, and that more bodyweight was lost in the acarbose-treated group. The authors concluded that acarbose is a viable choice for initial therapy in Chinese patients with newly diagnosed T2DM. ${ }^{26}$

This review summarizes the efficacy and safety of acarbose for treating Chinese patients with T2DM.

\section{Therapeutic efficacy Monotherapy}

The efficacy of acarbose in Chinese patients with T2DM has been confirmed in a number of controlled trials. ${ }^{20-26}$ Most of these studies were designed to assess the potential non-inferiority of acarbose compared with other therapeutic agents. These data confirmed that acarbose had similar efficacy to other anti-diabetic drugs, including vildagliptin, nateglinide, and metformin, in terms of reducing $\mathrm{HbA}_{1 \mathrm{c}}$ and fasting and postprandial glucose levels. Furthermore, acarbose was more effective at decreasing bodyweight than was vildagliptin and metformin in Chinese T2DM patients (Table 1). However, changes in bodyweight were not evaluated in three

Table I Comparison of effects of acarbose and other anti-diabetic agents

\begin{tabular}{|c|c|c|c|c|c|}
\hline Study & $\begin{array}{l}\text { Duration } \\
\text { (weeks) }\end{array}$ & $\begin{array}{l}\text { Drugs/ } \\
\text { comparators }\end{array}$ & Patients (n) & Main outcomes & Other outcomes \\
\hline Pan et $\mathrm{al}^{24}$ & 24 & Acarbose/vildagliptin & $44 I / 220$ & $\begin{array}{l}\text { Decreased } \mathrm{HbA}_{\mathrm{Ic}} \text { and fasting } \\
\text { plasma glucose were similar } \\
\text { in both groups }\end{array}$ & $\begin{array}{l}\text { Bodyweight was decreased more } \\
\text { in the acarbose group than in the } \\
\text { vildagliptin group }\end{array}$ \\
\hline Gao et $\mathrm{al}^{27}$ & 9 & Acarbose/nateglinide & $16 / 16$ & $\begin{array}{l}\text { Postprandial glucose was } \\
\text { decreased to a similar } \\
\text { extent in both groups }\end{array}$ & $\begin{array}{l}\text { Nateglinide significantly increased } \\
\text { postprandial insulin release and } \\
\text { decreased FFA concentrations }\end{array}$ \\
\hline Lu et $\mathrm{al}^{28}$ & 4 & Acarbose/nateglinide & $80 / 80$ & $\begin{array}{l}\text { Postprandial glucose was } \\
\text { decreased to a similar } \\
\text { extent in both groups }\end{array}$ & $\begin{array}{l}\text { Nateglinide improved lipid } \\
\text { metabolism under postprandial } \\
\text { conditions more than acarbose }\end{array}$ \\
\hline Zhou et $\mathrm{a}^{29}$ & 2 & Acarbose/nateglinide & $52 / 51$ & $\begin{array}{l}\text { AUCPP and IGP were } \\
\text { decreased to a similar } \\
\text { extent in both groups }\end{array}$ & $\begin{array}{l}\text { Both treatment groups exhibited } \\
\text { significantly improved intra- and } \\
\text { inter-day glycemic excursions }\end{array}$ \\
\hline Yang et $\mathrm{a}^{26}$ & 48 & Acarbose/metformin & $391 / 393$ & $\begin{array}{l}\mathrm{HbA}_{\text {Ic }} \text { was decreased to } \\
\text { a similar extent in both } \\
\text { groups }\end{array}$ & $\begin{array}{l}\text { Bodyweight was decreased more } \\
\text { in the acarbose group than in the } \\
\text { metformin group }\end{array}$ \\
\hline
\end{tabular}

Abbreviations: AUCPP, area under the curve of postprandial blood glucose; FFA, free fatty acid; $\mathrm{HbA}_{\mathrm{lc}}$, glycosylated hemoglobin; IGP, incremental glucose peak. 
studies $^{27-29}$ because they were short-term studies designed to compare the efficacy of acarbose and nateglinide (Table 1).

A 24-week study of 661 patients with T2DM compared the efficacy of acarbose (100 mg three times daily [tid]) and vildagliptin (50 mg twice daily [bid]). Similar reductions in fasting glucose $(1.5 \pm 0.2 \mathrm{mmol} / \mathrm{L}$ versus [vs] $1.2 \pm 0.1 \mathrm{mmol} / \mathrm{L})$ and $\mathrm{HbA}_{1 \mathrm{c}}(1.4 \% \pm 0.1 \%$ vs $1.3 \% \pm 0.1 \%)$ were observed in the vildagliptin and acarbose treatment groups, respectively. Although vildagliptin was weight-neutral $(0.4 \pm 0.1 \mathrm{~kg})$, there was a significant reduction in bodyweight in individuals treated with acarbose $(1.7 \pm 0.2 \mathrm{~kg})(P<0.001 \mathrm{vs}$ vildagliptin $){ }^{24}$

Recently, Yang et $\mathrm{al}^{26}$ performed a 48 -week study in 784 Chinese T2DM patients that compared the efficacy of acarbose (100 mg tid) and metformin (1,500 mg once daily [od]). At week 48, the reduction in $\mathrm{HbA}_{1 \mathrm{c}}$ levels was $1.11 \%$ (acarbose) and $1.12 \%$ (metformin). This study confirmed that acarbose had a similar efficacy to metformin in reducing $\mathrm{HbA}_{1 \mathrm{c}}$ in $\mathrm{T} 2 \mathrm{DM}$ patients. Furthermore, acarbose caused a greater loss of bodyweight than metformin (2.52 kg vs $1.89 \mathrm{~kg}, P=0.0194$ ) after 48 weeks of treatment.

Several short-term (2-9 weeks) studies in the People's Republic of China have confirmed that acarbose exerts similar hypoglycemic effects as nateglinide, particularly on postprandial glucose, ${ }^{27-29}$ although there were obvious differences in the mechanism of action of the two drugs. Nateglinide is an insulinotropic agent that exerts effects on $\beta$-cells to enhance early-phase insulin secretion. ${ }^{30,31}$ In contrast, acarbose represents a pharmacologic approach for modifying the digestion and absorption of dietary carbohydrates as an adjunct to dietary changes. Apart from hypoglycemic effects, nateglinide markedly decreased the concentrations of free fatty acids (FFAs) ${ }^{27,28}$ and increased insulin levels 30 minutes and 120 minutes after a standard meal, ${ }^{29}$ whereas acarbose had no effect on these parameters.

Impaired glucose tolerance (IGT), the intermediate metabolic stage between normal glucose homeostasis and diabetes, is a clinically significant major risk factor for T2DM and cardiovascular disease (CVD). Postprandial hyperglycemia is an important characteristic of IGT. Pan et $\mathrm{al}^{32}$ performed a study in which 252 Chinese patients with IGT were randomized to receive either $50 \mathrm{mg}$ tid acarbose therapy $(\mathrm{n}=125)$ or placebo $(n=127)$ for 16 weeks. In the intention-to-treat analysis, acarbose treatment caused significantly higher reductions in postprandial glucose and serum insulin concentrations compared with placebo. Triglyceride concentration was the only lipid parameter to be reduced significantly in acarbose-treated patients. Loss of bodyweight was also significantly greater in the acarbose group compared with placebo. During the study period, 19 individuals converted to overt T2DM ( 7 and 12 in the acarbose and placebo groups, respectively). This difference was not statistically significant; however, this might be due to the short duration of the study (16 weeks). The authors concluded that acarbose was efficacious for improving the metabolic state of individuals with IGT, suggesting potential beneficial effects for delaying or preventing the onset of T2DM in Chinese individuals.

AGIs regulate postprandial glucose levels mainly by delaying the absorption of glucose in the gastrointestinal $\operatorname{tract}^{13-15}$ and the gastric emptying rate, which further alters the secretion of insulin and glucagon by modulating the release of gut hormones, including gastric inhibitory polypeptide (GIP) and glucagon-like peptide (GLP)-1. In a Chinese study, 24 subjects were treated with acarbose for 24 weeks. Both fasting and postprandial plasma GLP-1 levels were increased at the end of the study period. ${ }^{33}$

Starch accounts for a higher proportion of total calories in an Eastern diet than in a Western diet; therefore, the hypoglycemic effects of acarbose might be greater in individuals who consume an Eastern diet. Studies assessing the efficacy and safety of acarbose performed in both mainland China and Taiwan reported that acarbose reduced $\mathrm{HbA}_{1 \mathrm{c}}$ levels by $1 \%$ to $1.5 \%{ }^{20,21}$ Similar studies performed in the USA, Germany, and Italy reported reductions of $0.7 \%, 1.8 \%$, and $0.14 \%$, respectively. ${ }^{34-36}$ A systematic meta-analysis comparing the hypoglycemic effects of acarbose monotherapy in patients with T2DM who consumed an Eastern or Western diet revealed that the hypoglycemic effects of acarbose were superior in T2DM patients who consumed an Eastern diet. The efficacy in these individuals was similar to that of sulfonylureas, metformin, and glinides. ${ }^{17}$

\section{Combination therapy}

Acarbose has been assessed in several randomized, doubleblinded trials as an add-on therapy to more established antidiabetic agents, such as sulfonylureas, metformin, and insulin in Chinese patients with T2DM.

\section{Acarbose as an add-on therapy to sulfonylureas}

In a multicenter, randomized, double-blinded study performed in the People's Republic of China, patients with insufficiently controlled blood glucose who received a fixed dose of sulfonylureas for 4 weeks before the study exhibited significantly reduced $\mathrm{HbA}_{1 \mathrm{c}}$ and blood glucose levels after 12 weeks of add-on treatment with acarbose $50 \mathrm{mg}$ tid. ${ }^{37} \mathrm{An}$ additional study of acarbose in Asian patients with T2DM 
that was inadequately controlled by diet and sulfonylureas revealed that treatment with acarbose $100 \mathrm{mg}$ tid for 24 weeks was associated with significantly greater reductions in $\mathrm{HbA}_{1 \mathrm{c}}$ ( $0.9 \%$ vs $0.13 \%, P=0.0018$ ) and 1 -hour postprandial blood glucose levels $(2.84 \mathrm{mmol} / \mathrm{L}$ vs $0.28 \mathrm{mmol} / \mathrm{L}, P=0.002)$ compared with placebo. ${ }^{38}$ These studies suggest that the use of acarbose in Asian patients with T2DM that is inadequately controlled by diet and sulfonylureas improves metabolic control and is safe and well tolerated.

\section{Acarbose as an add-on therapy to metformin}

The use of acarbose as an add-on therapy to sulphonylureas and/or metformin could further reduce blood glucose and $\mathrm{HbA}_{1 \mathrm{c}}$ levels in Chinese T2DM patients. ${ }^{38}$ Acarbose (50 mg tid) or glibenclamide (2.5 mg tid) were used as add-on drugs for 4 weeks in a population of adult Taiwanese patients with T2DM that was inadequately controlled by metformin monotherapy (1,500 mg od); the doses were then doubled in the subsequent 12 weeks. Although both agents could significantly reduce $\mathrm{HbA}_{1 \mathrm{c}}$ levels, the mean amplitude of glycemic excursions (MAGE) (5.6 mmol/L vs $4.0 \mathrm{mmol} / \mathrm{L}, P<0.001)$, bodyweight $(69.8 \mathrm{~kg}$ vs $68.3 \mathrm{~kg}, P<0.01)$, and serum triglycerides $(1.2 \mathrm{mmol} / \mathrm{L}$ vs $0.9 \mathrm{mmol} / \mathrm{L}, P<0.01)$ decreased only in patients treated with acarbose. ${ }^{39,40}$ A subsequent study, also performed in Taiwanese T2DM patients, suggested that 16 weeks of fixed-dose combination therapy with acarbose (50 mg tid) plus metformin (500 mg tid) resulted in significantly more T2DM patients reaching their $\mathrm{HbA}_{1 \mathrm{c}}$ goal compared with those receiving acarbose $50 \mathrm{mg}$ tid monotherapy (the proportion of patients who achieved $\mathrm{HbA}_{1 \mathrm{c}}<7.0 \%$ was $47.8 \%$ vs $10.7 \%$, respectively; $P<0.0001)$. Combination therapy also further reduced bodyweight compared with monotherapy ( $1.7 \mathrm{~kg}$ vs $1.0 \mathrm{~kg}$, respectively, $P<0.01)$. The authors concluded that acarbose/metformin fixed-dose combination therapy was well tolerated, with no significant risk of hypoglycemia; therefore, it might be a useful treatment for T2DM. ${ }^{41}$

\section{Acarbose as an add-on therapy to insulin}

A study was performed to evaluate the characteristics of glycemic variability in Chinese T2DM patients with $\mathrm{HbA}_{1 \mathrm{c}}<6.5 \%$. All patients were administered premixed insulin twice daily; 86 patients were also treated with acarbose $50 \mathrm{mg}$ tid for 2 weeks. A continuous glucose monitoring system was used to assess all patients. After combination therapy with acarbose, MAGE, and the mean of daily differences were decreased significantly compared with the insulin monotherapy group $(40 \%, P<0.01$ and $15 \%, P<0.05$, respectively). In addition, the incidence of hypoglycemic events was decreased significantly ( $2 \%$ vs $24 \%, P<0.01)$. This study concluded that combination therapy with premixed insulin bid with acarbose could reduce glycemic variability and decrease hypoglycemic events. ${ }^{42}$

Consistent with the above study, adjunctive therapy with acarbose $100 \mathrm{mg}$ tid provided an efficacious and safe method for improving glycemic control in Asian patients with T2DM that was insufficiently controlled with insulin. Specifically, combination therapy with acarbose caused greater reductions in $\mathrm{HbA}_{1 \mathrm{c}}(0.5 \%$ vs $0.2 \%, P=0.008)$ and 1 -hour postprandial glucose levels $(1.33 \mathrm{mmol} / \mathrm{L}$ vs $0.67 \mathrm{mmol} / \mathrm{L}, P=0.029)$ compared with placebo. ${ }^{43}$

\section{Effects of acarbose on cardiovascular disease}

Epidemiological data have suggested that hyperglycemia is a continuous risk factor for CVD, and that 2-hour postprandial glucose levels are more strongly associated with CVD than fasting glucose. Postprandial hyperglycemia plays a major role in vascular damage, particularly via non-traditional risk factors such as oxidative stress and subclinical inflammation. Data have suggested that acarbose could prevent this damage and reduce the risk of CVD. ${ }^{44}$

Acarbose can decrease the activity of the transcription factor nuclear factor kappa $\mathrm{B}(\mathrm{NF}-\kappa \mathrm{B})$ in the peripheral blood mononuclear cells of T2DM patients. NF- $\kappa \mathrm{B}$ activation is associated with inflammation, which leads to the development of endothelial dysfunction and atherosclerosis. ${ }^{45}$ Acarbose can also reduce the levels of coagulation markers and postprandial fibrinogen, reduce the circulating levels of cell adhesion molecules, and delay the thickening of the intima-media in patients with T2DM. ${ }^{46,47}$ Acarbose could also improve lipid profiles by reducing low-density lipoprotein (LDL) levels, leading to a significantly improved highdensity lipoprotein (HDL)/LDL ratio, and also by reducing postprandial hyperglycemia. In addition, acarbose reduces oxidative stress, endothelial dysfunction, dyslipidemia, and thrombosis in individuals with dysglycemia. ${ }^{48}$

The effects of acarbose on vascular damage translate into improved clinical outcomes in patients with both prediabetes and established T2DM. In the Study to Prevent Noninsulin-Dependent Diabetes Mellitus (STOP-NIDDM), acarbose reduced the risk of any cardiovascular event by $49 \%$ and absolute risk by $2.5 \%$ compared with placebo. ${ }^{48}$ In a sub-study of STOP-NIDDM, acarbose treatment was associated with a $\sim 50 \%$ reduction in the annual mean increase 
in intima-media thickness. ${ }^{49}$ Furthermore, a meta-analysis of studies assessing the use of acarbose in patients with T2DM suggested a significant reduction in CVD-related events. ${ }^{50}$

Although there is no direct evidence that acarbose could reduce the risk of CVD in Chinese T2DM patients, it could effectively reduce many CVD risk factors in this patient population, including postprandial hyperglycemia, MAGE, $\mathrm{HbA}_{1 \mathrm{c}}$, lipid parameters, and bodyweight. ${ }^{27-32,37-43}$

\section{Safety and tolerability Side effects}

Clinical and surveillance studies have revealed that acarbose treatment is associated with very few serious side effects. ${ }^{51}$ The most common side effects reported to date are mildto-moderate gastrointestinal disorders, such as flatulence, abdominal distension, diarrhea, and dyspepsia, which arise from the fermentation of undigested carbohydrates by colonic bacteria in the large intestine. These disorders usually subside as treatment continues, which might be due to increased $\alpha$-glucosidase activity in the lower segments of the small intestine. Gastrointestinal disorders are always transient and moderate if treatment is started at low doses and then increased gradually.

Following oral administration, acarbose is only absorbed into the systemic circulation to a very minor extent $(<2 \%)$; consequently, systemic side effects are not normally anticipated. Indeed, no systemic side effects of acarbose have been reported in the clinical studies performed to date. Specifically, there were no significant changes in complete blood counts, urine analysis, and blood chemistry values over time. ${ }^{37}$ Acarbose was well tolerated irrespective of patient age, pre-treatment, or the number of concomitant diseases. Moreover, clinical trials assessing acarbose revealed that it was well tolerated, and that the adverse experience profile was clinically acceptable. ${ }^{25}$ A dose of acarbose $100 \mathrm{mg}$ tid, alone or in combination with other anti-diabetic drugs, was safe and well tolerated in Chinese T2DM patients. ${ }^{23-25,38,52}$ Nevertheless, the dose might need to be reduced in patients with troublesome gastrointestinal symptoms.

\section{Risk of hypoglycemia}

The current approach to diabetes treatment consists of multi-drug regimens. However, concerns have been raised regarding intensive glucose control and the possibility that the rapid reduction in $\mathrm{HbA}_{1 \mathrm{c}}$ levels might result in increased mortality, ${ }^{53}$ possibly as a result of increased hypoglycemia. ${ }^{54,55}$ Therefore, it is important to recognize that acarbose is associated with a low incidence of hypoglycemia in Chinese or Asian individuals, ${ }^{38-42}$ suggesting that it is suitable for use in combination therapy. If blood glucose falls into the hypoglycemic range when acarbose is prescribed with other agents such as sulphonylureas, metformin, or insulin, the prescribed dose of the co-administered agent might need to be decreased.

\section{Contraindication}

AGIs are contraindicated in patients with known hypersensitivity to the drug, in individuals with diabetic ketoacidosis, inflammatory bowel disease, colonic ulceration, or partial intestinal obstruction as well as those predisposed to intestinal obstruction. They are also contraindicated in patients with chronic intestinal diseases associated with marked digestion or absorption disorders and those with conditions that might deteriorate as a result of increased gas formation in the intestine. ${ }^{56}$

\section{Conclusion}

Acarbose is a potential option for the treatment of Chinese T2DM patients. It is effective, safe, and well tolerated, both as a monotherapy and as an add-on to additional antidiabetic agents in patients with uncontrolled T2DM. The hypoglycemic effects of acarbose are similar to those of sulfonylureas, metformin, and glinides. However, it elicits superior effects on reducing bodyweight and glycemic variability in Chinese T2DM patients. Acarbose is safe and well tolerated, and is associated with a low incidence of gastrointestinal adverse effects; it is well accepted for the treatment of diabetes in Chinese patients. Acarbose is a viable choice for use as an initial therapy in Chinese patients with newly diagnosed T2DM.

\section{Disclosure}

The authors report no conflicts of interest in this work.

\section{References}

1. No authors listed. Retinopathy and nephropathy in patients with type 1 diabetes four years after a trial of intensive therapy. The Diabetes Control and Complications Trial/Epidemiology of Diabetes Interventions and Complications Research Group. N Engl J Med. 2000;342(6):381-389.

2. No authors listed. Intensive blood-glucose control with sulphonylureas or insulin compared with conventional treatment and risk of complications in patients with type 2 diabetes (UKPDS 33). UK Prospective Diabetes Study (UKPDS) Group. Lancet. 1998;352(9131):837-853.

3. Choi YJ, Kim HC, Kim HM, Park SW, Kim J, Kim DJ. Prevalence and management of diabetes in Korean adults: Korea National Health and Nutrition Examination Surveys 1998-2005. Diabetes Care. 2009;32(11): 2016-2020.

4. Alberti KG, Zimmet P, Shaw J. International Diabetes Federation: a consensus on Type 2 diabetes prevention. Diabet Med. 2007;24(5): $451-463$. 
5. Holman RR, Paul SK, Bethel MA, Matthews DR, Neil HA. 10-year follow-up of intensive glucose control in type 2 diabetes. $N$ Engl J Med. 2008;359(15):1577-1589.

6. DECODE Study Group, the European Diabetes Epidemiology Group. Glucose tolerance and cardiovascular mortality: comparison of fasting and 2-hour diagnostic criteria. Arch Intern Med. 2001;161(3): 397-405.

7. Meigs JB, Nathan DM, D’Agostino RB Sr, Wilson PW; Framingham Offspring Study. Fasting and postchallenge glycemia and cardiovascular disease risk: the Framingham Offspring Study. Diabetes Care. 2002;25(10):1845-1850.

8. Levitan EB, Song Y, Ford ES, Liu S. Is nondiabetic hyperglycemia a risk factor for cardiovascular disease? A meta-analysis of prospective studies. Arch Intern Med. 2004;164(19):2147-2155.

9. Monnier L, Colette C, Boniface H. Contribution of postprandial glucose to chronic hyperglycaemia: from the "glucose triad" to the trilogy of "sevens". Diabetes Metab. 2006;32 Spec No 2:2S11-16.

10. Woerle HJ, Neumann C, Zschau S, et al. Impact of fasting and postprandial glycemia on overall glycemic control in type 2 diabetes. Importance of postprandial glycemia to achieve target $\mathrm{HbA} 1 \mathrm{c}$ levels. Diabetes Res Clin Pract. 2007;77(2):280-285.

11. Peter R, Okoseime OE, Rees A, Owens DR. Postprandial glucose: a potential therapeutic target to reduce cardiovascular mortality. Curr Vasc Pharmacol. 2009;7(1):68-74.

12. Wang JS, Tu ST, Lee IT, et al. Contribution of postprandial glucose to excess hyperglycaemia in Asian type 2 diabetic patients using continuous glucose monitoring. Diabetes Metab Res Rev. 2011;27(1):79-84.

13. Standl E, Schnell O. Alpha-glucosidase inhibitors 2012 - cardiovascular considerations and trial evaluation. Diab Vasc Dis Res. 2012;9(3): 163-169.

14. Lebovitz HE. Alpha-Glucosidase inhibitors. Endocrinol Metab Clin North Am. 1997;26(3):539-551.

15. Scheen J, Lefèbvre PJ. Oral antidiabetic agents. A guide to selection. Drugs. 1998;55(2):225-236.

16. Scheen AJ. Is there a role for alpha-glucosidase inhibitors in the prevention of type 2 diabetes mellitus? Drugs. 2003;63(10):933-951.

17. Zhu Q, Tong Y, Wu T, Li J, Tong N. Comparison of the hypoglycemic effect of acarbose monotherapy in patients with type 2 diabetes mellitus consuming an Eastern or Western diet: a systemic meta-analysis. Clin Ther. 2013;35(6):880-899.

18. Hu FB. Dietary pattern analysis: a new direction in nutritional epidemiology. Curr Opin Lipidol. 2002;13(1):3-9.

19. Food and Agriculture Organization of the United Nations. FAO Food and Nutrition Paper 83. Globalization of Food Systems in Developing Countries: Impact on Food Security and Nutrition. Rome: UN FAO; 2004. Available from: http://www.fao.org/docrep/007/y5736e/ y5736e00.htm. Accessed January 15, 2013.

20. Pan CY, Landen H. Post-marketing surveillance of acarbose treatment in patients with type 2 diabetes mellitus and subjects with impaired glucose tolerance in China. Clin Drug Investig. 2007;27(6):397-405.

21. Hung YJ, Kuo SW, Wang CH, Chang HY, Hsieh SH, Landen H. Postmarketing surveillance of acarbose treatment in Taiwanese patients with type 2 diabetes mellitus. Clin Drug Investig. 2006;26(10):559-565.

22. Wang H, Ni Y, Yang S, Li H, Li X, Feng B. The effects of gliclazide, metformin, and acarbose on body composition in patients with newly diagnosed type 2 diabetes mellitus. Curr Ther Res Clin Exp. 2013;75: $88-92$.

23. Chan JC, Chan KW, Ho LL, et al. An Asian multicenter clinical trial to assess the efficacy and tolerability of acarbose compared with placebo in type 2 diabetic patients previously treated with diet. Asian Acarbose Study Group. Diabetes Care. 1998;21(7):1058-1061.

24. Pan C, Yang W, Barona JP, et al. Comparison of vildagliptin and acarbose monotherapy in patients with type 2 diabetes: a 24-week, double-blind, randomized trial. Diabet Med. 2008;25(4):435-441.

25. Li CL, Hung YJ, Qamruddin K, Aziz MF, Stein H, Schmidt B. International noninterventional study of acarbose treatment in patients with type 2 diabetes mellitus. Diabetes Res Clin Pract. 2011;92(1):57-64.
26. Yang W, Liu J, Shan Z, et al. Acarbose compared with metformin as initial therapy in patients with newly diagnosed type 2 diabetes: an openlabel, non-inferiority randomised trial. Lancet Diabetes Endocrinol. 2014;2(1):46-55.

27. Gao HW, Xie C, Wang HN, Lin YJ, Hong TP. Beneficial metabolic effects of nateglinide versus acarbose in patients with newly-diagnosed type 2 diabetes. Acta Pharmacol Sin. 2007;28(4):534-539.

28. Ju-Ming L, Xiao-Hui G, Xiao-Feng L, Yan-Bing L, Li Y, Yao-Ming X. Effects of nateglinide on postprandial plasma glucose excursion and metabolism of lipids in Chinese patients with type 2 diabetes: 4-week, randomized, active-control, open-label, parallel-group, multicenter trial. Curr Med Res Opin. July 19, 2012. [Epub ahead of print.]

29. Zhou J, Li H, Zhang X, et al. Nateglinide and acarbose are comparably effective reducers of postprandial glycemic excursions in Chinese antihyperglycemic agent-naive subjects with type 2 diabetes. Diabetes Technol Ther. 2013;15(6):481-488.

30. Li J, Tian H, Li Q, et al. Improvement of insulin sensitivity and beta-cell function by nateglinide and repaglinide in type 2 diabetic patients a randomized controlled double-blind and double-dummy multicentre clinical trial. Diabetes Obes Metab. 2007;9(4):558-565.

31. Hazama Y, Matsuhisa M, Ohtoshi K, et al. Beneficial effects of nateglinide on insulin resistance in type 2 diabetes. Diabetes Res Clin Pract. 2006;71(3):251-255.

32. Pan CY, GaoY, Chen JW, et al. Efficacy of acarbose in Chinese subjects with impaired glucose tolerance. Diabetes Res Clin Pract. 2003;61(3):183-190.

33. Zheng MY, Yang JH, Shan CY, et al. Effects of 24-week treatment with acarbose on glucagon-like peptide 1 in newly diagnosed type 2 diabetic patients: a preliminary report. Cardiovasc Diabetol. 2013;12:73.

34. Buse J, Hart K, Minasi L. The PROTECT Study: final results of a large multicenter postmarketing study in patients with type 2 diabetes. Precose Resolution of Optimal Titration to Enhance Current Therapies. Clin Ther. 1998;20(2):257-269.

35. Mertes G. Efficacy and safety of acarbose in the treatment of type 2 diabetes: data from a 2-year surveillance study. Diabetes Res Clin Pract. 1998;40(1):63-70.

36. Scorpiglione N, Belfiglio M, Carinci F, et al. The effectiveness, safety and epidemiology of the use of acarbose in the treatment of patients with type II diabetes mellitus. A model of medicine-based evidence. Eur J Clin Pharmacol. 1999;55(4):239-249.

37. Wu QL, Liu YP, Lu JM, et al. Efficacy and safety of acarbose chewable tablet in patients with type 2 diabetes: a multicentre, randomized, double-blinded, double-dummy positive controlled trial. J Evid Based Med. 2012;5(3):134-138.

38. Lin BJ, Wu HP, Huang HS, et al. Efficacy and tolerability of acarbose in Asian patients with type 2 diabetes inadequately controlled with diet and sulfonylureas. J Diabetes Complications. 2003;17(4):179-185.

39. Wang JS, Lin SD, Lee WJ, et al. Effects of acarbose versus glibenclamide on glycemic excursion and oxidative stress in type 2 diabetic patients inadequately controlled by metformin: a 24 -week, randomized, openlabel, parallel-group comparison. Clin Ther. 2011;33(12):1932-1942.

40. Lin SD, Wang JS, Hsu SR, et al. The beneficial effect of $\alpha$-glucosidase inhibitor on glucose variability compared with sulfonylurea in Taiwanese type 2 diabetic patients inadequately controlled with metformin: preliminary data. J Diabetes Complications. 2011;25(5):332-338.

41. Wang JS, Huang CN, Hung YJ, et al; Acarbose/Metformin Fixed-Dose Combination Study Investigators. Acarbose plus metformin fixed-dose combination outperforms acarbose monotherapy for type 2 diabetes. Diabetes Res Clin Pract. 2013;102(1):16-24.

42. Su JB, Wang XQ, Chen JF, Wu G, Jin Y. Glycemic variability in insulin treated type 2 diabetes with well-controlled hemoglobin A1c and its response to further treatment with acarbose. Chin Med J (Engl). 2011;124(1):144-147.

43. Hwu CM, Ho LT, Fuh MM, et al; Asian Acarbose Study Group. Acarbose improves glycemic control in insulin-treated Asian type 2 diabetic patients: results from a multinational, placebo-controlled study. Diabetes Res Clin Pract. 2003;60(2):111-118. 
44. Båvenholm PN, Efendic S. Postprandial hyperglycaemia and vascular damage: the benefits of acarbose. Diab Vasc Dis Res. 2006;3(2): 72-79.

45. Rudofsky G Jr, Reismann P, Schiekofer S, et al. Reduction of postprandial hyperglycemia in patients with type 2 diabetes reduces NF-kappaB activation in PBMCs. Horm Metab Res. 2004;36(9): 630-638.

46. Ceriello A, Taboga C, Tonutti L, et al. Post-meal coagulation activation in diabetes mellitus: the effect of acarbose. Diabetologia. 1996;39(4):469-473.

47. Tschoepe D. Decreased fibrinogen by treatment with the alphaglucosidase inhibitor acarbose [ADA abstract 766]. Diabetes. 2004; 53(Suppl 2):A189.

48. Chiasson JL, Josse RG, Gomis R, et al; STOP-NIDDM Trial Research Group. Acarbose treatment and the risk of cardiovascular disease and hypertension in patients with impaired glucose tolerance: the STOPNIDDM trial. JAMA. 2003;290(4):486-494.

49. Hanefeld M, Chiasson JL, Koehler C, Henkel E, Schaper F, TemelkovaKurktschiev T. Acarbose slows progression of intima-media thickness of the carotid arteries in subjects with impaired glucose tolerance. Stroke. 2004;35(5):1073-1078.
50. Hanefeld M, Cagatay M, Petrowitsch T, Neuser D, Petzinna D, Rupp M. Acarbose reduces the risk for myocardial infarction in type 2 diabetic patients: meta-analysis of seven long-term studies. Eur Heart J. 2004;25(1):10-16.

51. Hanefeld M. Cardiovascular benefits and safety profile of acarbose therapy in prediabetes and established type 2 diabetes. Cardiovasc Diabetol. 2007;6:20.

52. Derosa G, Maffioli P. Efficacy and safety profile evaluation of acarbose alone and in association with other antidiabetic drugs: a systematic review. Clin Ther. 2012;34(6):1221-1236.

53. Action to Control Cardiovascular Risk in Diabetes Study Group, Gerstein HC, Miller ME, et al. Effects of intensive glucose lowering in type 2 diabetes. $N$ Engl J Med. 2008;358(24):2545-2559.

54. Bonds DE, Miller ME, Bergenstal RM, et al. The association between symptomatic, severe hypoglycaemia and mortality in type 2 diabetes: retrospective epidemiological analysis of the ACCORD study. BMJ 2010;340:b4909.

55. Dluhy RG, McMahon GT. Intensive glycemic control in the ACCORD and ADVANCE trials. N Engl J Med. 2008;358(24):2630-2633.

56. Derosa G, Maffioli P. $\alpha$-Glucosidase inhibitors and their use in clinical practice. Arch Med Sci. 2012;8(5):899-906.
Therapeutics and Clinical Risk Management

\section{Publish your work in this journal}

Therapeutics and Clinical Risk Management is an international, peerreviewed journal of clinical therapeutics and risk management, focusing on concise rapid reporting of clinical studies in all therapeutic areas, outcomes, safety, and programs for the effective, safe, and sustained use of medicines. This journal is indexed on PubMed Central, CAS,

\section{Dovepress}

EMBase, Scopus and the Elsevier Bibliographic databases. The manuscript management system is completely online and includes a very quick and fair peer-review system, which is all easy to use. Visit http://www.dovepress.com/testimonials.php to read real quotes from published authors.

Submit your manuscript here: http://www.dovepress.com/therapeutics-and-clinical-risk-management-journal 